\title{
ANALISE VAN DIE TSWANARAAISEL
}

\section{INLEIDING}

'n Strukturcle, stilisticsc en funksionele beskrywing van die Twanaraaisel bring mee dat daar aan die volgende aspektc aandag gegec moet word:

- Wat is 'n raaisel en loc word dit in Tswana genoem.

- Tot watter studiegebied en literêre genre hoort dic raaisel en watter subvorme kan vir Tswana onderskei word.

- Hoc sien die struktuur van Tswanaraaisels daar uit.

- Deur wie, waar, wanncer en hoe word Tswanaraaiscls voorgedra.

- Watter stilistiese kenmerke kan in Tswanaraaisels onderskei word.

- Watter funksies vervul raaisels in 'n 'Tswanagemeenskap.

\section{WA'T IS 'N RAAISEL EN HOE WORD DIT IN TSWANA GENOEM?}

\subsection{Wat is 'n raaisel}

Daar bestaan talle definisies en omskrywings van wat 'n raaisel is (Georges en Dundes, 1963:113, Guma, 1967:39, Gowlett, 1979:47, Cole-Bcuchat, 1957:133, Schapera, 1932:215). Die belangrikste kenmerke wat deur bogenoemde persone uitgelig word, is die volgende:

- Die raaisel is tradisionecl omdat dit mondeling van die cen geslag na die ander oorgedra word.

- Dit is ' $n$ verbale uitdrukking en val dus in die kader van tradisionele mondelinge gebruike.

- Dit bestaan ook uit een of meer beskrywende elemente waarin leidrade vir die identifisering van 'n bepaalde objek of item voorgehou word en dan geraai moet word wat dit is.

Met inagneming van bogenoemde kenmerke kan 'n raaisel soos volg omskryf word: 
Dit is 'n taalspel waarin versluierde semanties-distinktiewe kenmerke van 'n bepaalde objek voorgehou word wat daartoe aanleiding kan gee dat die regtc ekwivalent geraai of verskal moet word. 'n Soeke word op tou gesit om die regte antwoord te verskaf.

Vergelyk dic volgende voorbeelde:

Raaisel: Diphiri tsê tlhano tsê di tsênang mô mosimêng. $V y f$ wolwe wat in ' $n$ gat ingaan.

Antwoord: Ke menwana

Dit is vingers

Raaisel: Thotlhora boupi o jê kgêtsi.

Skud die meel uit en eet dic sak.

Antwoord: Ke mogôdu.

Dit is ' $n$ pens.

\subsection{Wat word 'n raaisel in Tswana genoem?}

Raaiscls staan in Tswana onder verskeie name bekend. Vergelyk Cole, 1931:523:

Ekv.

nyôba/nywaba

Iclepa mv.

dinyôba/dinywaba

malepa

By hierdie lys kan volgens Schapera (1931:215) ook gevoeg word:

Ekv.

thabalakane

thabalakwane mv.

dithabalakane

dithalakwane

Thabalakwane is slegs 'n variante vorm van cersgenoemde. Uit die dric benamings word thabalakwane/dithabalakwane as die mees tiperende en die algemeenste woord voorgestel.

\section{DIE STUDIEGEBIED EN LITERERE GENRE WAARTOE DIE TWSANARAAISEL HOORT}

Die bestudering van die raaisel word veral deur twee studiegebicde opgeëis, $\mathrm{nl}$. die folklore en lefterkunde. Dit bring mee dat dic raaisel deur hierdie twee 
dissiplines vanuit verskillende perspektiewe en standpunte bestudeer word. Hierdie dualisticse optrede veruorsaak soms dat bestudering van raaisels vir die belangstellende persoon heelwat teenstrydighede verskaf.

\subsection{Folklore eis die bestudering van die raaisel op}

Die bestudering van die raaisel word veral deur die folklore opgeëis (Dundes, 1965:5, Dorson, 1972:15-20, Die Woordeboek van dic Afrikaanse Taal, Taylor, 1965:19, Francis Lec Utley, 1965:17). Dit word gesien as geestelike besit wat in mondelinge vorm oorgedra word. Daar word na raaiscls gekyk en daarmee gehandel as veral 'n aspek van kultuur en as sodanig word slegs maatstawwe aangelê om die kulturele waarde daarvan te bepaal.

\subsection{Die letterkunde eis die bestudering van die raaisel op}

Finnegan (1970:1-25) sien die mondelinge folklore (ook die raaisel) as horende tot die studiegebied "oral literalure". Hiermec word die studie van die raaisel binne die arena van die letterkunde ingetrek. Dit bring mec dat dic literĉr-wetenskaplike norme ook op die bestudering van die raaisel toegepas kan word.

\subsection{Die plek wat die raaisel tussen die studiegebiede inneem}

Dic plek wat die raaisel tussen die twee studiegebiede inneem asook die litererêre genre waartoe dit hoort kan soos volg voorgestel word (Swanepoel, 1982:8):

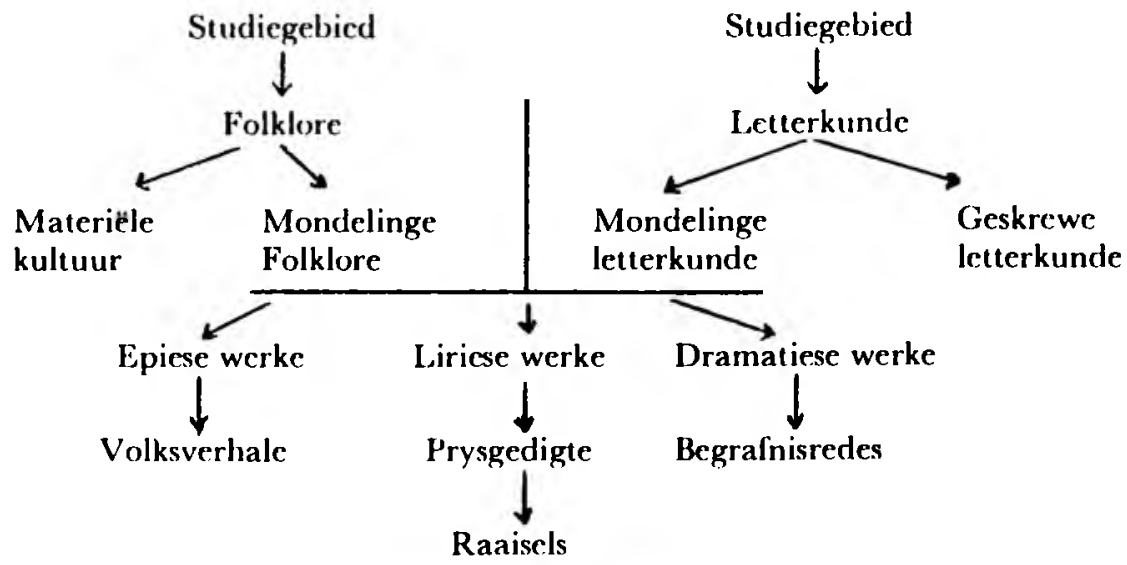


Raaisels kan vanweë die wyse waarop die taalclemente in die samestelling daarvan gebruik word, as horende tot die liriese werke geklassifiseer word. Die volgende subvorme van die raaisel in Bantoetale word deur Gowlett (1979:47-65) onderskei:

- Ware raaisels. Dit is die raaisels wat uit een of meer sememe (samcstellende dele) opgebou is d.w.s. raaisels waarin daar sekere semanties-distinktiewe kenmerke van 'n voorwerp gegee word.

- Spreckwoordraaisels. Dit is raaisels waarin spreekwoorde voorkom.

- Tweetalige raaisels. In hierdie raaisels is die raaisel en antwoord in verskillende tale.

- Toonraaisels. In hierdie raaisels is daar ' $n$ ooreenkoms in toon tussen die raaisel en dic antwoord.

- Probleemraaiscls. Dit is raaisels wat heelwat langer as die ander tipe raaisel is, en waarin daar ook nie 'n duidelike ooreenkoms tussen die raaisel en die antwoord is nie.

- Gebonde raaiscls. Dit is raaisels wat ' $n$ vaste vorm het en nie gewysig kan word nie.

Van al hierdie subvorme wat onderskei word, kom slegs ware raaisels in Tswana voor.

\section{DEUR WIE, WAAR, WANNEER EN HOE WORD TSWANA- RAAISELS VOORGEDRA}

\subsection{Wie vra raaisels}

Dic vra van Tswanaraaisels is 'n aktiwiteit wat gewoonlik deurjongmense of kinders beoefen word. Dit kan persone van beide geslagte wees. Twee persone is gewoonlik by dic vra van raaiscls betrokke maar groepe kan ook hierby betrokke wees. In laasgenoemde geval word die vra en antwoord van die raaisel gewoonlik deur die leier van die groep waargeneem. Soms kan enige persoon uit 'n grocp ook hierdie rol vervul. Volwasse persone neem slegs by uitsondering aan die vra van raaisels deel. Dit kom slegs voor waar jonges touwys gemaak word in die wyse waarop raaisels gevra word. 


\subsection{Waar en wanneer word raaisels gevra}

Raaisels kan op enige plek en enige tyd voorgeclra word. Die vra van raaisels is ' $n$ familiegelcentheid en as sodanig word dit gewoonlik in die huis, laugs die vuur, by die veepos co/of êrens op die werf voorgedra. Alhoewel die desdac byna enige tyd gevra kan word, het dit meestal in dic aand plaasgevind wanneer die dagtaak afgehandel is. Die rustige verwyl van tyd het veral aanleiding daartor gegec. Dit was taboe om raaisels gedurende die dag voor te dra (Junod, 1927:22, Dipale, 1978:18). Dit is ontmordig omtlat dic dagtaak, oppas van vec, huiswerk en allerliande take, daaronder sou lei. Die hedendaagse geslag is bewus hiervan maar steur hulle nie meer daaraan nie.

\subsection{Hoe word die raaisels gevra}

Die genot wat persone uit raaiscls put, is geleë in dic wyse waarop die kompetisie tussen die iwee part ye verloop. Om 'n raaisel te vra staan bekend as go thaba dithabalakivane.

Een party begin deur 'n raaiscl te vra en hou vol daarmee solank die tečparty die raaisels oplos d.w.s. die regte antwoord verskal. Hierdie proses word voortgesit totclat daar nie 'n antwoord verskal kan word nie. Die persoon wat begin het, sê dan: $A$ di tle marêkua / Laal hulle gekoop woord. Die aanvanklike teëparty vervul nou die rol van vraer totdat die persoon wat begin het ook vasgevra is. Eersgenoemde (aanvanklike tec̈party) sê dan: Mpolêllề ya gago!/sê my joune!

Nadat die antwoord verskaf is, sê hy dan: Le nna ya me ke ... / Myne ook, is ...

Hierdic proses word herhaal en dic persoon wat die meeste korrek kan antwoord, is die wenner.

\section{DIE STRUKTUUR VAN TSWANARAAISELS}

\subsection{Algemeen}

Volgens Gcorges en Dundes (1963:113) onderskei Petsch vyfelemente in die struktuur van 'n raaisel, $\mathrm{nl}$.

i. Introduction frame element - the formulae to introducc riddles.

ii. Denominative kerncl element - the response from the audience to the riddler asking what is he going to riddle about. 
iii. Descripive kernel element - the riddle itself.

iv. Block element - positive or negative.

v. Concluding frame element - the element which conclude the riddle.

Hadebe (1979:57) het hierdie struktuur met geringe wysigings op Zoeloe tocgepas. Met dic struktuur soos uiteengesit deur Petsch, en dic toepassing van Hadebe kan die struktuur van Tswanaraaisels soos volg uitecngesit word:

\subsection{Bekendstellingsformule}

Dit is clie inisiële gedeelte waardeur die atmosfeer geskep word sodat raaisels gevra kan word. Dic volvorm wat onderskei word is:

Mpolêllê dilô, o mpolêllê gore ...

Sê vir my iets, sề vir my dat ...

Verkorte vorme kom voor nadat die regte atmosfeer geskep is, $\mathbf{n l}$.

Mpolêllê gore ...

Sê vir my dat ...

Mpolêllê ...

Sî̀ vir my ...

\subsection{Respons van die wedyweraar}

Dit kom gewoonlik aan dic begin voor en dui aan dat die uit daging aanvaar word.

Ke tla go bolêlla

Ek sal jou sê (antwoord)

\subsection{Die raaiselligaam}

Die raaisel word volledig voorgedra, bv.

Metse mô mpêng ya thaba.

Statte aan die kant (pens) van 'n berg. 


\subsection{Die vraag word dan gestel, $\mathrm{nl}$.}

Ke cng?

Wat is dit?

\subsection{Heropvraging}

Indien die wedyweraar nic goed gehoor het of goed verstaan het nie, kan die raaisel weer opgevra word. Dit word hoogstens tweekeer tocgelaat. Daar word gevra:

E boêlêtsê!

Herhaal dit!

Botsa gapế re utlwê!

Vra weer dat ons kan hoor!

Boĉlêtsa!

Herhaal!

\subsection{Die antwoord kan dan verskaf word:}

Ke ditsêtbê

Dit is ore

\subsection{Blokkering}

Hier verskaf die vraesteller die uitslag van die raaisels, $\mathrm{nl}$.

Go siame!

Dit is goed/reg!

O a fosa!

Jy het dit verkeerd.

\subsection{Verdere verskaffing van antwoord}

Dit word slegs vir 'n tweede keer toegelaat waarby weer 'n blokkering plaasvind.

Voorbeeld:

A. Mpolêllê dilô, o mpolêllê gore ...

Sê vir my iets, sê vir my dat ... 
B. Ke tla go bolêlla.

Ek sal vir jou sĉ.

A. Sedilsana sê se sa kgaleng.

'n Fonteintjic wat nie droog word nie.

A. Ke eng?

Wat is dit.

B. Boêlêtsa!

Herhaal!

A. Sedibana sê sc sa kgalêng.

'I Fontcintjie wat nic droog word nic.

B. Ke molomo.

Dit is 'n mond.

A. Go siame.

Dit is gocd/reg.

Hierdic struktuur word gewysig en kan in verkorte vorme gegec word solank dit verstaan word. Dit word ook baic be invloed deur die stemming tydens die proses van raaiselvra.

\section{DIE STILISTIESE KENMERKE VAN DIE TWSANARAAISEL}

Die raaisel moet soos in 3.3 aangetoon is, gesien word as 'n subgenre van die mondelinge letterkunde. Dit is daaroun belangrik dat literêr-weterıskaplike maatslawwe toegepas word in dic evalucring daarvan. Die volgende is die mees uitstaande stilistiese kenmerke van die Tswanaraaisel.

\subsection{Die gebruik van ideofone}

Ideofone speel 'n belangrike rol in raaisels. Cole (1955:370) omskryf 'n ideofoon soos volg:

Idcophones are vivid vocal images or representatives of visual, auditory, and other sensory or mental experiences.

'n Voorbecld waarin hierdie funksies vervul word is: 
Raaisel: Bana ba makgoa laa dutsế mô ditulông. 'Thêlêlê, ba ilê!

Blanke kinders sit op stocle. Woerts weg is hulle.

Antwoord: Ke menwana

Dit is vingers.

Die beweging van die vingers wanneer 'n hand toegemaak word, word hicrmee treffend voorgestel.

\subsection{Verkleining en vergroting}

Die dinninutiel' agtervoegsel word baie aan naamwoorde gesuffigecr. Dit word veral gednen deur groot voorwerpe as klein voor te stel en sodoende 'n leidraad te verskaf wat maklik geraai kan word.

Raaisel: Basimanyane ba ba tlolang dithaba tsôtlhê.

Seunijies wat oor al die berge spring.

Antwoord: Ke matlhô.

Dit is ö.

Raaiscl: Dithabana tsê pêdi fa thoko ga tsela.

Twee bergies langs 'n pad.

Antwoord: Ke mabêlê.

Lit is borste.

Vergroting:

In sommige raaisels word sekere objekte voorgchou as baic groot terwyl hulle in der waarheid klein is.

Raaisel: Rrê o na le tshemo ê kgolo fêla mabêlê a têng le legôfi ga a tlale. Vader het 'n groot land maar die koring, daarin maak nie' $n$ hand vol nie.

Antwoord: Ke unoriri

Dit is hare.

Die hare op 'n mens se hoof word vergelyk met die graan op 'n groot land.

\subsection{Metafore}

Metafore kom baie in raaisels voor juis ondat in 'n metafoor die a-normale beklemtoun word. Die verband tussen die antword en dit wat geïmplisecr word, kan baie goed in 'n metafoor verhul word. 
Raaiscl: Dipudi tsê di golêgilwêng mô tshingwanêng. Bokke wat in 'n tuin vasgemaak is.

Antwoord: Ke mapluutshe.

Dit is pampoene.

Bokke wat in ' $n$ tuin vasgemaak is, is soos pampoene wat aan die stoel met hulle ranke verbind is.

Raaiscl: Ntlo e tshwêu e se nang lebati.

'n Wit huisic wat nie 'n deur het nie.

Antwoord: Ke lee.

Dit is 'n eier.

'n Wit huisie wat nie 'n deur het nie is beslis 'n eier.

\subsection{Eufemisme}

Eufemismes kom ook algemeen in raaisels voor. Kinders word veral hierdcur gelcer om sekere dinge en verskynsels met respek en eerbied te behandel. ' $n$ Voorbeeld hiervan is:

Raaisel: Mêtsana mô le thabana môlê.

Watertjies hier en 'n bergie daar.

Antwoord: Ke moroto le mascpa

Dit is urine en ontlasting.

\subsection{Humor}

Humor is ook 'n integrale deel van raaisels. Die volgende voorbeelde illust reer dit baic duidclik:

Raaisel: Mma ntshwarê ke nyê.

Ma houvas iny dat ek kan ontlas.

Antwoord: Ke nkô.

Dit is 'n neus.

Raaisel: Sa ntswa sc ka kwa morago, sa motho se ka kwa pele.

' $n$ Hond s'n is agter ' $n$ mens s' $n$ is daar voor. 
Antwoord: Ke mangole

Dit is knicë.

Raaiscl: Mo apolê moscse o jê monate.

Trek haar rok uit en cet lekker (eet die lekkerte).

Antwoord: Ke dikgôbê

Dit is kabocmiclies.

\subsection{Samestellings}

Samestellings kom ook algemeen voor omdat in cen so 'n woord 'n groot omhaal van woorde saamgeval word.

Raaisel: Nônyane tsa masĉlakgakala.

Voc̈ls van ver-gaan-kossock.

Antwoord: Ke matlhô.

Dit is oë.

Raaisel: Lapa la Mmasckôkôthêlang.

Skcrmmuur moeder-slaan-dit-in.

Antwoord: Ke mĉnô

Dit is tande.

\subsection{Antonieme}

Antonicme kom dikwels voor en verhoog dic raaiselagtigheid van hierdic genre.

Raaisel: Tśsłwêu ya wêla, ntsho e a tlhatloga.

Dic witte claal af en dic swarte gaan op.

Antwoord: Ke boupi le lentswê.

Dit is meel en 'n maalklip.

\subsection{Balans en ritme}

Dit is 'n kenmerk wat eie is aan die raaisel omdat dit liriesc kuns is.

Raaiscl: Hutsênyana lee, ê nngwe lec.

Die hoedjie 'n eier, die ander deel onk 'n eier. 
Antwoord: Ke lefulô le maswi.

Dit is skuim cn melk.

\subsection{Woordherhalings}

Herhalings van woorde dra veral by tot die ritme van raaiscls.

Raaisel: Satampatampa sa ya go tsalêla falê.

Dit gaan sy eic koers en gee geboorte daar.

Antwoord: Ke lekatane.

Dit is 'n makataan.

\subsection{Bevelvorm}

Omdat dit mondelinge woordkuns is, kom die bevelvorm ook baie voor.

Raaisel: Tlhotlhora boupi o jê kgêtsi!

Skud die meel uit en eet die sak!

Antwoord: Ke mogodu.

Dil is ' $n$ pens.

\section{DIE FUNKSIES WAT RAAISELS IN DIE TWSANAGEMEENSKAP VERVUL}

Raaisels is 'n integrale deel van die 'I'wsana se kultuur en tradisie. Dit vervul die volgende funksies in dic gemeenskap:

- Dic vra van raaisels word veral ter wille van die ontspanningswaarde daarvan gevra.

- Dit is ook ' $n$ middel waarmee intellektuele vermoë en vlugheid van denke mee getocts word.

- Raaisels maak ook gebruik van velerlei taalkundige clemente en as sodanig word 'T'swana daardeur verryk.

- Dit stimuleer kinders orn voorwerpe rondom hulle waar te necm en lê ook 'n liefde vas vir latere ontwikkeling van prysdigters. 


\section{SAMEVATTING}

Die bestudering van dic raaiscl is ' $n$ terrein wat beslis in dic tockoms aandag moet geniet omdat dit 'n taal-en kult uurskat is van onskatbare waarde. Dit is ook mondelinge taalkuns en die moderne tegnologie van klank- en beeldapparaat kan liierdie volkskuns bewaar en van 'n toekoms verseker.

\section{BRONNELYS}

BROWN, J.T. 1931. Secwana Dictionary. London Missionary Society. COLE, D.T. 1955. An introluction to Tswana Grammar. Kaapstad: Longmans, Green \& Co.

COLE-BEUCHAT'I, P.D. 1957. Riddles in Bantu. African Situdies, vol. 16, no. 3 .

DIPALE, A. 1978. "Meila ya Setswana" in Boswa no. I.

DORSON, R.M. 1972. African folklore. New York: Anchor Books.

DUNDES, $\Lambda$. (redl.) 1965. 'The study of folklore. Londen: Prentice-Hall. FINNEGAN, R. 1970. Oral literature in Africa. Olal, Oxlord: Clarendon Press.

GEORGES, R.A. \& DUNDES, A. 1963. Towards a structural definition of the ridclle. Journal of American folklore, vol. 76.

GOWLETT, D.F. 1979. A structural typology for Bantu Riddles. African Situdies.

GUMA, S.M. 1967. The form content and technique of traditional literature in Southern Sotho. Pretoria: J.L. van Schaik, Ltd.

HAIEBE, S.B. 1979. "Structural and stylistic analysis of Zulu riddles" in Derde Afrikatale kongres, Wentzel, P.J. Unisa.

JUNOD, H.A. 1972. The life of a South African tribe. New York: University Books.

SCHAPERA, 1. 1932. Kgatla riddles and their significance. Bantu Studies, no. 6.

SWANEPOEL, S.A. 1982. Die 'T'swanavolksverhaal. Ongepublisecrde proefskrif, UNISA.

TAYLOR, A. 1965. "Folklore and the student of literature" in The study of folklore, van Dundes, A. London: Prentice-Hall.

UTLEY, F.L. 1965. "On defining folklore in The study of folklore, van Dundes $A$. London: Prentice-Hall.

WOORDEBOEK VAN DIE AFRIKAANSE IAAL, dl. D-F. Pretoria: Staatsdrukker. 1950-1968. 